\title{
Postinfectious ocular flutter
}

Supplemental data at www.neurology.org
A 31-year-old pregnant woman presented 1 week after an upper respiratory tract infection with rapid, conjugated periodic ocular oscillations, occurring in horizontal bursts (see the video on the Neurology ${ }^{\circledR}$ Web site at www.neurology.org) and truncal ataxia. After 14 weeks, all signs resolved without treatment.

Postinfectious ocular flutter and truncal ataxia is a rare entity previously described after infections with enterovirus, mumps, cytomegalovirus, and HIV. Recently, an association with the ganglioside antibody anti-GQ1b was suggested, supporting an autoimmune pathogenesis. ${ }^{1}$ The course of the disease is usually benign with spontaneous resolution.

Michael Waisbourd, MD, and Anat Kesler, MD, Tel Aviv, Israel

Disclosure: The authors report no disclosures.

Address correspondence and reprint requests to Dr. Michael Waisbourd, Department of Ophthalmology, Tel Aviv Sourasky Medical Center, 6 Weizmann Street, Tel Aviv 64239, Israel; mwaisbourd@hotmail.com

1. Zaro-Weber O, Galldiks N, Dohmen C, et al. Ocular flutter, generalized myoclonus, and trunk ataxia associated with antiGQ1b antibodies. Arch Neurol 2008;65:659-661. 


\title{
Neurology
}

\author{
Postinfectious ocular flutter \\ Michael Waisbourd and Anat Kesler \\ Neurology 2009;72;1027 \\ DOI 10.1212/01.wnl.0000344416.19427.cc
}

This information is current as of March 16, 2009

\section{Updated Information \& Services}

\section{Supplementary Material}

\section{References}

\section{Subspecialty Collections}

Permissions \& Licensing

Reprints including high resolution figures, can be found at: http://n.neurology.org/content/72/11/1027.full

Supplementary material can be found at: http://n.neurology.org/content/suppl/2009/03/14/72.11.1027.DC1

This article cites 1 articles, 0 of which you can access for free at: http://n.neurology.org/content/72/11/1027.full\#ref-list-1

This article, along with others on similar topics, appears in the following collection(s):

All Neuro-ophthalmology

http://n.neurology.org/cgi/collection/all_neuroophthalmology

Gait disorders/ataxia

http://n.neurology.org/cgi/collection/gait_disorders_ataxia

Ocular motility

http://n.neurology.org/cgi/collection/ocular_motility

Post-infectious

http://n.neurology.org/cgi/collection/postinfectious_

\section{Viral infections}

http://n.neurology.org/cgi/collection/viral_infections

Information about reproducing this article in parts (figures,tables) or in its entirety can be found online at:

http://www.neurology.org/about/about_the_journal\#permissions

Information about ordering reprints can be found online:

http://n.neurology.org/subscribers/advertise

Neurology ${ }^{\circledR}$ is the official journal of the American Academy of Neurology. Published continuously since 1951, it is now a weekly with 48 issues per year. Copyright . All rights reserved. Print ISSN: 0028-3878. Online ISSN: 1526-632X.

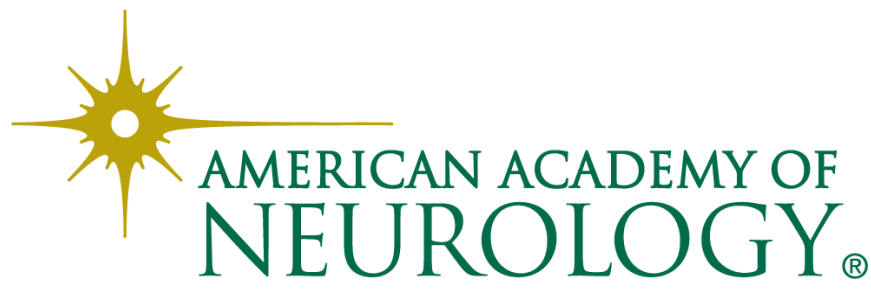

